\title{
Micronization of Cetirizine Using Rapid Expansion of Supercritical Carbon Dioxide
}

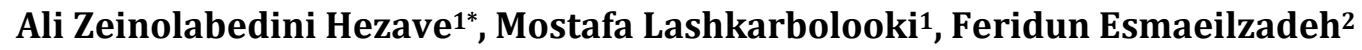 \\ ${ }^{1}$ Islamic Azad University, Dashtestan Branch, Borazjan, Iran \\ ${ }^{2}$ Chemical and Petroleum Engineering Department, School of Engineering, Shiraz University, Shiraz, Iran \\ Email: ${ }^{*}$ Zeinolabedinihezave.ali@gmail.com
}

Received 5 April 2015; accepted 24 April 2015; published 29 April 2015

Copyright (C) 2015 by authors and OALib.

This work is licensed under the Creative Commons Attribution International License (CC BY).

http://creativecommons.org/licenses/by/4.0/

(c) $\underset{\mathrm{EY}}{\mathrm{B}}$ Open Access

\begin{abstract}
During the past decades, producing micro- and nano-particles of drugs is gaining attention since it is possible to modify the solubility of insoluble drugs in the gastronical fluids significantly. Respect to this fact, in the current investigation, rapid expansion of supercritical carbon dioxide (RESS) for fabricating the micro-particles of cetirizine is investigated. In this way, different operational conditions including extraction pressure (160 - 220 bar), extraction temperature $(308$ - $328 \mathrm{~K})$, nozzle length $(1-8 \mathrm{~mm})$, and nozzle diameter $(450-1700 \mu \mathrm{m})$ are examined. The performed experiments revealed that among the examined operational conditions, nozzle diameter and extraction pressure introduce significant effects on the reduction of particle size compared with the other examined parameters. The results revealed that it is possible to reduce the cetirizine particles from $98.52 \mu \mathrm{m}$ to $0.53 \mu \mathrm{m}$ using RESS. In addition, scanning electron microscopy (SEM) analysis is performed to investigate the effect of different operational parameters on the morphology of the particles of cetirizine. The results demonstrate that RESS not only is able to reduce the particle size of the cetirizine, but also is able to change the morphology of the cetirizine particles from the irregular shape to spherical form.
\end{abstract}

\section{Keywords}

Cetirizine, RESS, Micronization, SEM

Subject Areas: Chemical Engineering \& Technology, Drugs \& Devices, Nanometer Materials

\section{Introduction}

In the science of drug and pharmaceutical production, high solubility rate of the drug powders is an essential parameter helping the pharmaceutical developers toward more effective products. Unfortunately, there are many

\footnotetext{
"Corresponding author.
}

How to cite this paper: Hezave, A.Z., Lashkarbolooki, M. and Esmaeilzadeh, F. (2015) Micronization of Cetirizine Using Rapid Expansion of Supercritical Carbon Dioxide. Open Access Library Journal, 2: e1277. 
kinds of drugs exhibiting poor solubility in water and gastronical fluids bounding their application. Poorly water-soluble drug candidates often merge from contemporary drug discovery programs, and present formulators with considerable technical challenges [1]. In more details, many newly proposed and produced drugs suffer from poor water solubility, consequently leading to major hurdles in the design of suitable formulations for administration to patients. Regarding this shortcoming, the development of techniques and materials to overcome these hurdles is a major area of research in pharmaceutical companies.

One of the proposed techniques to overcome this problem is reducing the particle size of the particles. In more details, it has been proven that dissolution rate is a function of the surface area of the particles. On the other hand, solubility, is a direct function of total surface area for a dispersed phase, and is inversely related to particle size according to the expression, $S v=6 / d$, where $S v$ is the specific surface area and $d$ is the average particle diameter [2]. Based on this fact, if the size of the particle reduces, the solubility will increase.

In the way of reducing particle size, several techniques have been reported that the common technique for the preparation of micron-size drugs is the mechanical comminution (e.g., by crushing, grinding, and milling) of previously formed larger particles. Although, these techniques are successful in some extend, they introduce several drawbacks (e.g. high amount of energy and alteration of drug substance properties and surface properties in a mainly uncontrolled manner) [3].

In this way, during the past two decades, the researchers were seeking for methods which produce drug particles in micron- or nano-levels (with narrow particle size distribution), and the drug particles experience no changes in their physicochemical properties. One of the successful methods for producing high-quality drug powders with narrow particle size distribution is supercritical fluid (SCF) based technologies [4]-[10]. This high capability rises from the unique advantages of the supercritical fluids which are good diffusivity of gases and good solubility of liquids. It is possible to develop products of standardized concentration of active ingredients, or produce pharmaceutical products of much higher concentration [11]. Among the different possible solvents, carbon dioxide $\left(\mathrm{CO}_{2}\right)$ is one of the most widely used solvents since it introduces unique properties including being environmentally-friendly, non-toxic, inflammable, cheap and highly available. Generally there are two common supercritical fluid based technologies for producing micron- or nano-size particles of drug powders including rapid expansion of supercritical solution (RESS) [5] [12]-[19]. There are two major branches in this technology: 1) rapid expansion of supercritical solution and 2) GAS technique and its branches [20]. The RESS process is consisted of two different sections including extraction and precipitation units. In the first section, the solutes are dissolved in a SCF. After loading the supercritical fluid with the solute, an extremely fast phase change from the supercritical to the gas-like state takes places during the expansion in the supersonic free-jet. This leads to high super-saturation (about 109) and formation of fine particles, and consequently solubility and bioavailability of the drug will enhance due to particle size reduction [11] [21] [22]. In the RESS method there are different operational conditions that can be manipulated to engineer particle based on the requirements. Among these operational conditions, the most effective parameters are extraction pressure; extraction temperature, expansion chamber characterization, co-solvent, concentration of solute and nozzle configuration will influence the particle size and morphology of the manufactured particles [23].

Although all the parameters are important to obtain the best results, nozzle and its characterization have a critical role in the RESS process. In many studies, capillary nozzles or laser-drilled nozzles were applied to manufacture micron- and submicron-level particles [24]-[26]. Based on some studies, it was considered that smaller nozzle in diameter will cause fine or ultra-fine particles [27] [28]. Usually, the diameters of the used nozzle are about $40-200 \mu \mathrm{m}$, because producing smaller laser-drilled nozzle is not easy [29].

Since the production of laser drilled nozzles is costly and needs unique technologies, a new kind of nozzle was designed and constructed by the coauthors whose applicability and functionality were established previously [29]-[39].

In this way, since there is no report about the micronization of the cetirizine particles using RESS methods based on the best knowledge of the authors, in the current investigation cetirizine is selected as the model drug. For this purpose, several operational parameters including extraction pressure (160 - 220 bar), temperature (308 $328 \mathrm{~K})$, nozzle length $(2-11 \mathrm{~mm})$ and diameter $(450-1700 \mu \mathrm{m})$ are examined to find if RESS process is feasible to fabricate micron- or submicron-level particles in size. Cetirizine is a non-sedating antihistamine with molecular weight of $388.888 \mathrm{~g} \cdot \mathrm{gmol}^{-1}$ which works similarly to the other second generation antihistamines, loratadine (Claritin), fexofenadine (Allegra) and azelastine (Astelin). Histamine is a chemical that is responsible for many of the signs and symptoms of allergic reactions, for example, swelling of the lining of the nose, sneezing, 
and itchy eyes.

\section{Experimental Procedure}

\subsection{RESS Apparatus}

The RESS experiments were performed using a homemade apparatus rated for maximum operating temperature and pressure of $353 \mathrm{~K}$ and 400 bar, respectively (see Figure 1). A brief description of the used apparatus is as follow; at first, the gaseous $\mathrm{CO}_{2}$ supplied from a cylinder capsule was passed through a filter and then was liquefied using a refrigerator. After liquefaction, it was pumped by a reciprocating oil-free water-free high pressure manual pump (Haskel, USA) into a vertical surge tank. The surge tank was used to dampen the pressure fluctuations produced by operation of the manual pump. The surge tank was equipped with a bourdon gauge in the range of $0-400$ bar by a division of 1 bar which gives the operator the ability of easy controlling of the pressure during the experiments.

The pressurized $\mathrm{CO}_{2}$ then entered into an extraction vessel $(180 \mathrm{ml})$ fulfilled with a basket including the powder of cetirizine packed with glass beads for preventing channeling phenomenon. In more details, a specific amount of cetirizine powder was mixed with glass beads to enhance the contact surface between the cetirizine powder and supercritical carbon dioxide enhances the solubility of cetirizine in supercrtic.al and preventing channeling of high-pressure carbon dioxide through the bed. The temperature of the surge tank and equilibrium vessel were controlled using a hot water jacket surrounded these sections. In addition, the temperature of the system was sensed by a PT-100 thermocouple control the temperature using PID controlling protocol with accuracy of $0.1^{\circ} \mathrm{C}$. The noteworthy point is that the outlet port of the equilibrium cell was covered by glass wool to ensure that during the expansion of the supercritical solution through the nozzle no undissolved drug particles will carry over the SC- $\mathrm{CO}_{2}$ flow. After preparing the basket containing the drug powder and glass bead, it was then placed into an extraction vessel and was held in the desired conditions for about $3 \mathrm{~h}$ to ensure that complete equilibrium has been obtained. After that, the equilibrated solution was then expanded by a pre-heated fine needle valve into a nozzle. The fine needle valve was pre-heated to compensate the heat loss because of the Joule Thomson effect and to prevent the nozzle clogging during the expansion. The precipitated particles were collected on the stubs and analyzed by a SEM to monitor the particle size and morphology.

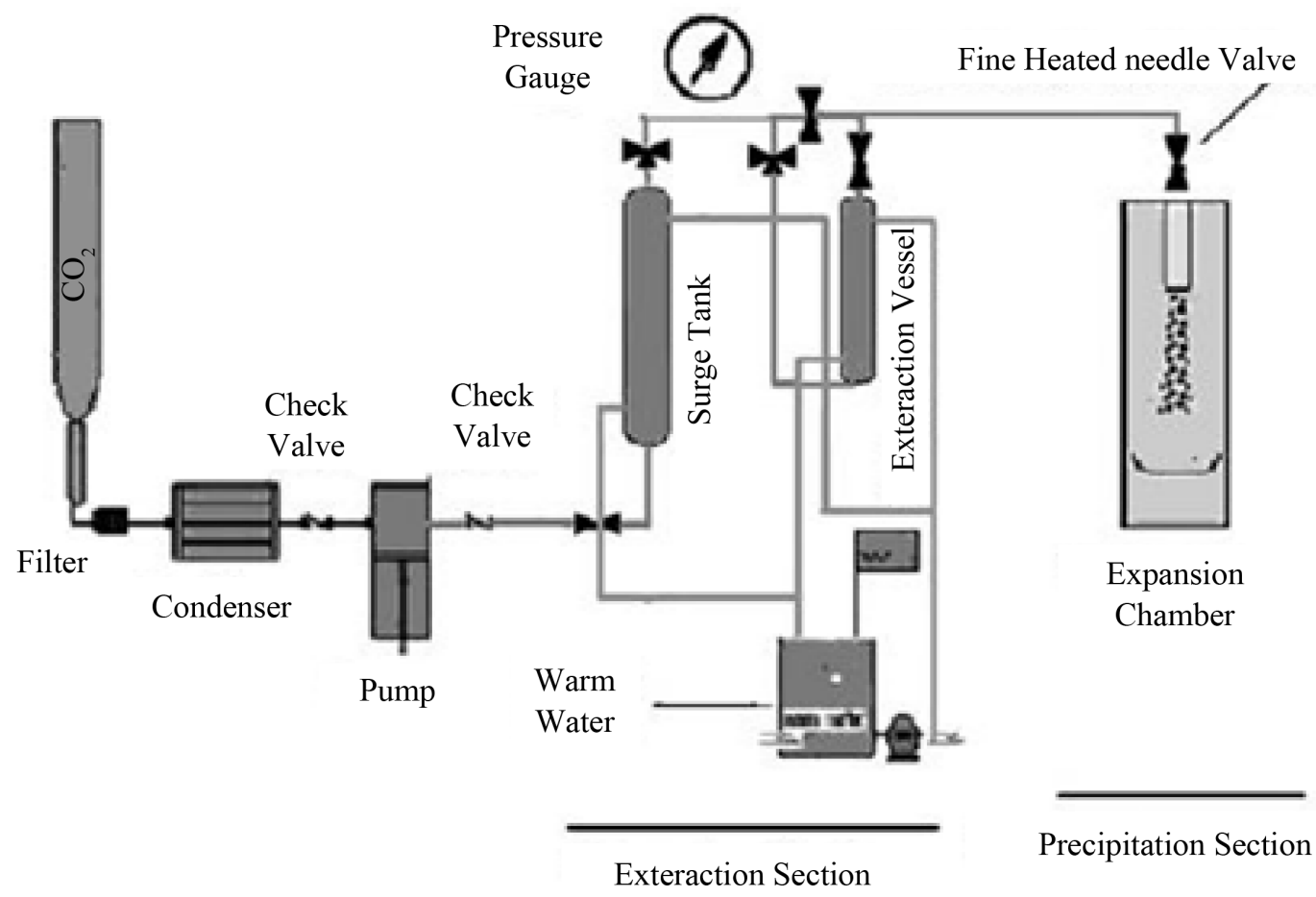

Figure 1. The schematic of the used apparatus. 


\subsection{Materials}

Cetirizine was kindly supplied from Alma Concept Company (France), and used as received. In addition, the $\mathrm{CO}_{2}(99.9 \%<$ purity) was supplied from Abughadareh Gas Chemical Company, Iran. The mean particle size of the original cetirizine was about $98.52 \mu \mathrm{m}$, respectively (see Figure 2, Table 1).

\subsection{Particle Size and Morphology}

The morphology and size of the precipitated particles were examined using scanning electron microscopy (SEM) (S360-CAMBRIDGE). In brief, prior to examine the samples by a SEM the precipitated cetirizine particles were collected on the conductive stubs which were then coated by a sputter-coater (SC-7640-Polaron) with Pd-Pt in the presence of argon $(99.9 \%$ < purity) at room temperature for a period of $100 \mathrm{~s}$ under an accelerating voltage of $20 \mathrm{kV}$. The mean particle size of the precipitated particles was calculated by counting about 100 particles, arbitrarily selected. The mean particle size was calculated by a written program which randomly selected 100 particles of the SEM images.

\subsection{Nozzle Configuration}

The structure of the new nozzle is illustrated in Figure 3. The nozzle comprises two parts, shell part and inside part. In this design, the clearance between the inside part and the nozzle acts as a circular orifice so that supercritical fluids can spray from a narrow exit in a few microns.

Also the swirled channel enhances the chance of the formation of spherical form particles which could be helpful to improve the morphology of particles. In the entrance of the nozzle, $\mathrm{SC}-\mathrm{CO}_{2}$ is introduced through the spiral channel, so the fluids can be swirled out of the nozzle. In this kind of nozzle instead of the usual diameter, the effective nozzle diameter has been defined as follows:

$$
D_{\text {Effective }}=2 \sqrt{\frac{S_{\text {Effective }}}{\pi}}
$$

where $S_{\text {Effective }}=S_{\text {Shell }}-S_{\text {Inside. }}$. The calculated effective diameters for the experiments are given in Table 2 .

\section{Results and Discussions}

In the current investigation, 12 different experiments were performed to find the effect of different operational parameters including extraction pressure (160 - 220 bar), extraction temperature (308 - $328 \mathrm{~K}$ ), nozzle length (2 - $11 \mathrm{~mm})$ and nozzle diameter (450 - $1700 \mu \mathrm{m})$.

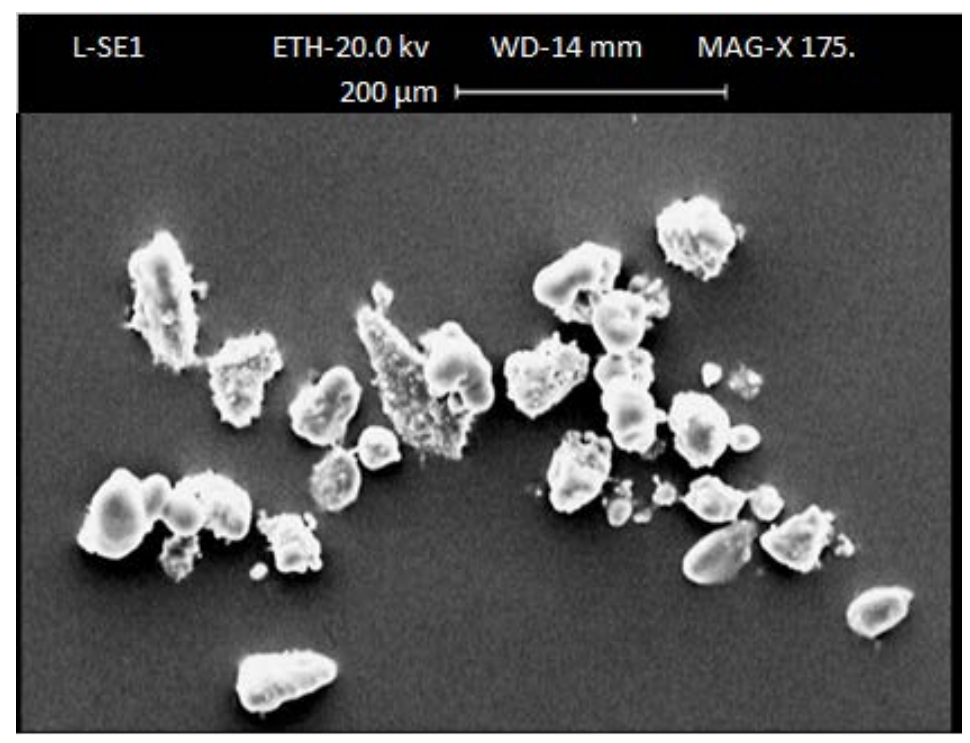

Figure 2. The SEM image of intact particles of cetirizine. 


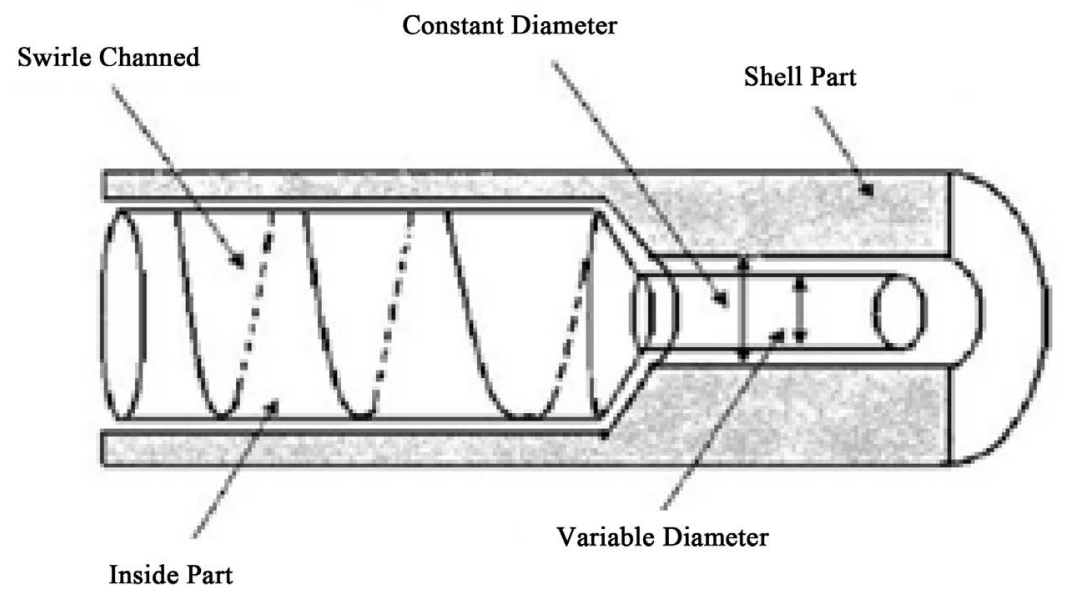

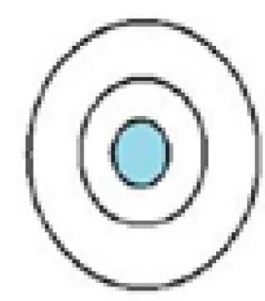

$\mathrm{S}_{\text {Inside }}$

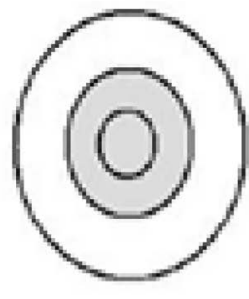

$\mathrm{S}_{\text {sholl }}$

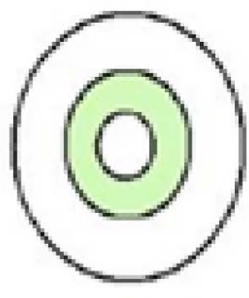

Capillary

Figure 3. Schematic diagram of the used nozzle: (a) side view and (b) front view.

Table 1. The physicochemical properties of the cetirizine [40].

\begin{tabular}{|c|c|c|c|c|c|c|}
\hline $\begin{array}{l}\text { Molecular } \\
\text { formula }\end{array}$ & $\begin{array}{l}\text { CAS } \\
\text { number }\end{array}$ & $\begin{array}{c}\text { Critical } \\
\text { pressure (bar) }\end{array}$ & $\begin{array}{c}\text { Critical } \\
\text { temperature (K) }\end{array}$ & $\begin{array}{l}\text { Acentric } \\
\text { factor }\end{array}$ & $\begin{array}{l}\text { Average molecular } \\
\text { weight }\left(\mathrm{g} \cdot \mathrm{gmol}^{-1}\right)\end{array}$ & Structure \\
\hline $\mathrm{C}_{21} \mathrm{H}_{25} \mathrm{ClN}_{2} \mathrm{O}_{5}$ & 83881-51-0 & $17.50^{\mathrm{a}}$ & $1025.1^{\mathrm{a}}$ & $0.783^{\mathrm{b}}$ & 388.888 & \\
\hline
\end{tabular}

${ }^{\mathrm{a}}$ These properties are estimated using Joback method (Ref. [41]); ${ }^{\mathrm{b}}$ The acentric factor was estimated using Ref. [41].

Table 2. Calculated effective nozzle diameters.

\begin{tabular}{ccc}
\hline Constant diameter $(\mathrm{mm})$ & Variable diameter $(\mathrm{mm})$ & Effective diameter $(\mu \mathrm{m})$ \\
\hline 5.4 & 5.38 & 450 \\
5.4 & 5.36 & 650 \\
5.4 & 5.32 & 900 \\
5.4 & 5.30 & 1000 \\
5.4 & 5.28 & 1200 \\
5.4 & 5.12 & 1700 \\
\hline
\end{tabular}




\subsection{Effect of Extraction Pressure}

In the first stage of this investigation, the effect of extraction pressure in the range of 160 bar to 220 bar on the size and morphology of the cetirizine particles were investigated while the other operating conditions including extraction temperature $(318 \mathrm{~K})$, nozzle length $(5 \mathrm{~mm})$ and nozzle diameter $(1700 \mu \mathrm{m})$ were kept constant. The obtained results revealed that as the pressure increases from 160 bar to 220 bar, the mean particle size of the precipitated cetirizine particles reduces from $12.68 \mu \mathrm{m}$ to $7.60 \mu \mathrm{m}$. This observed trend can be described based on the solubility of cetirizine in the supercritical carbon dioxide (see Figure 4). In more details, Hezave et al. [40] has been reported that the molar solubility of cetirizine in the supercritical carbon dioxide increases from $3.62 \times 10^{-5}$ to $2.15 \times 10^{-4}$ as the pressure increases from 160 bar to $240 \mathrm{bar}$ for isothermal of $318 \mathrm{~K}$. They have

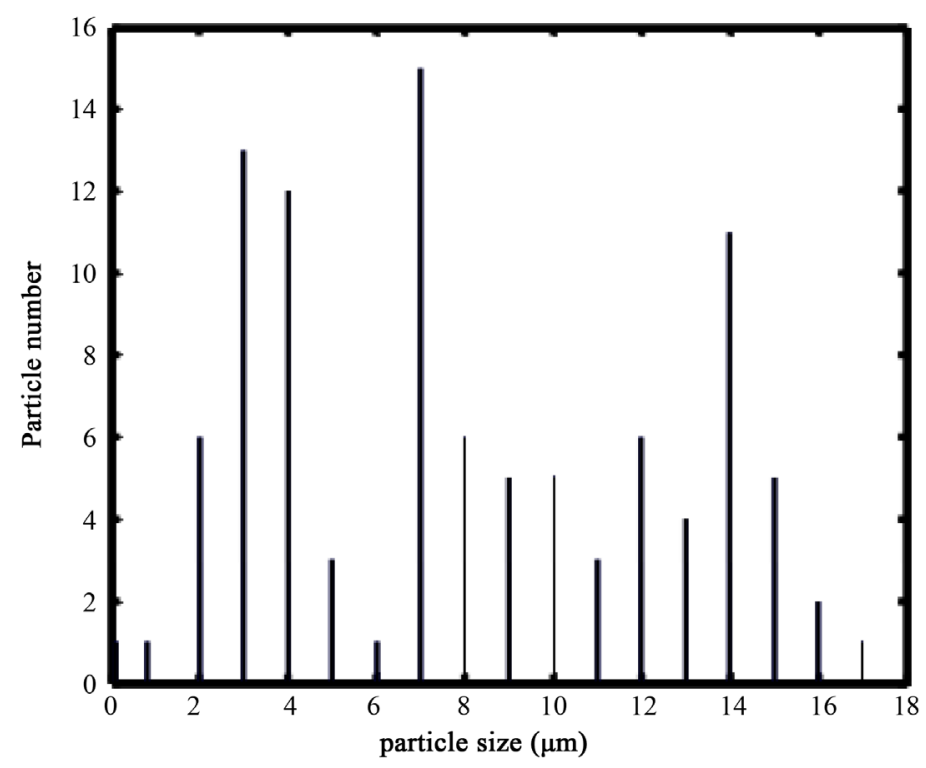

(a)

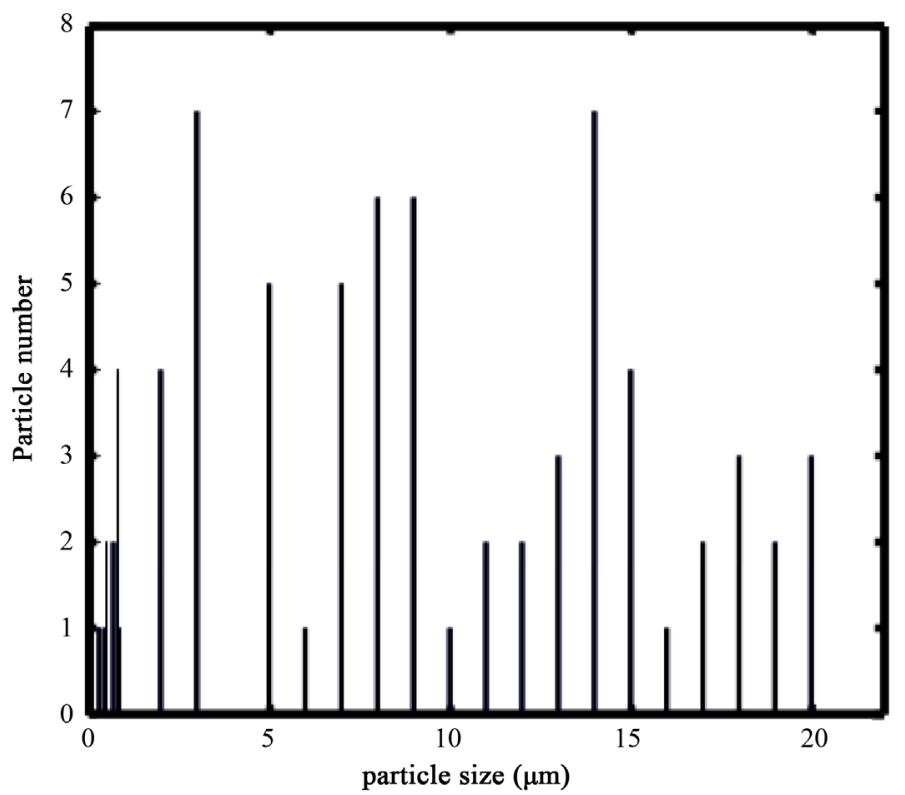

(b)

Figure 4. Effect of extraction pressure on the mean particle size of the precipitated particles, (a) $\mathrm{P}_{\mathrm{ext}}=220$ bar and (b) $\mathrm{P}_{\mathrm{ext}}=160$ bar $\left(\mathrm{T}_{\mathrm{ext}}=318\right.$ $\mathrm{K}, \mathrm{L}_{\text {nozzle }}=5 \mathrm{~mm}$ and $\left.\mathrm{D}_{\text {nozzle }}=1700 \mu \mathrm{m}\right)$. 
been reported that an increase in the operating pressure from 160 to 400 bar at all the isotherms resulted in an increase in cetirizine solubility. This observed trend was related to this fact that as the pressure increases the intermolecular space between the $\mathrm{CO}_{2}$ molecules reduces consequently increases the density of supercritical carbon dioxide and interactions between the cetirizine and $\mathrm{CO}_{2}$ molecules. As results the solubility of cetirizine in the supercritical carbon dioxide enhances consequently results higher super-saturations in the fluid upon expansion. According to classical theory of nucleation, higher super-saturation leads higher nucleation rate and the particle volume is inversely proportional to the nucleation rate; our above results appear to agree with simple theoretical predictions [42]. Similar results were obtained by Liu and Nagahama [43], Wang et al. [44], Huang et al. [42], Yildiz et al. [45] and our previous works [20] [21] for naphthalene, titanocene Dichloride, aspirin, salicylic acid, mefenamic acid and ketoprofen, respectively. However, Reverchon et al. [46] obtained an opposite result for the effect of extraction pressure on salicylic acid particles. The difference in results may be explained by different experimental conditions or nozzle configuration.

\subsection{Effect of Temperature}

In the second stage of this study, the effect of extraction temperature in the intervals of 308, 318 and $328 \mathrm{~K}$ was investigated while the other operational conditions including extraction pressure (220 bar), nozzle length (5 mm) and nozzle diameter $(1700 \mu \mathrm{m})$ were kept constant during the experiments. The obtained results demonstrated that there no clear trend for the effect of extraction temperature on the particle size of precipitated particles was observed. By the way, in the previous study [40] the authors have found that cetirizine $+\mathrm{SC}-\mathrm{CO}_{2}$ experiences a cross over pressure about 200 bar. In more details, the solubility of cetirizine decreases as the temperature increases for pressures lower than 200 bar while for higher pressures, an increase in the temperature leading to an increase in the solubility of cetirizine. Based on these findings, it seems that since the examined extraction pressure was about 220 bar which is not so far from the cross over pressure, no obvious trend was observed for the effect of extraction temperature. But the point is worth mentioning is that the morphology of the precipitated particle are somehow move toward more spherical shape compared to the intact particles of the cetirizine (see Figure 5). Finally, since no obvious trend on the effect of extraction temperature was observed, the extraction temperature for rest of the experiments were held at $318 \mathrm{~K}$ since smaller parties were precipitated using this value.

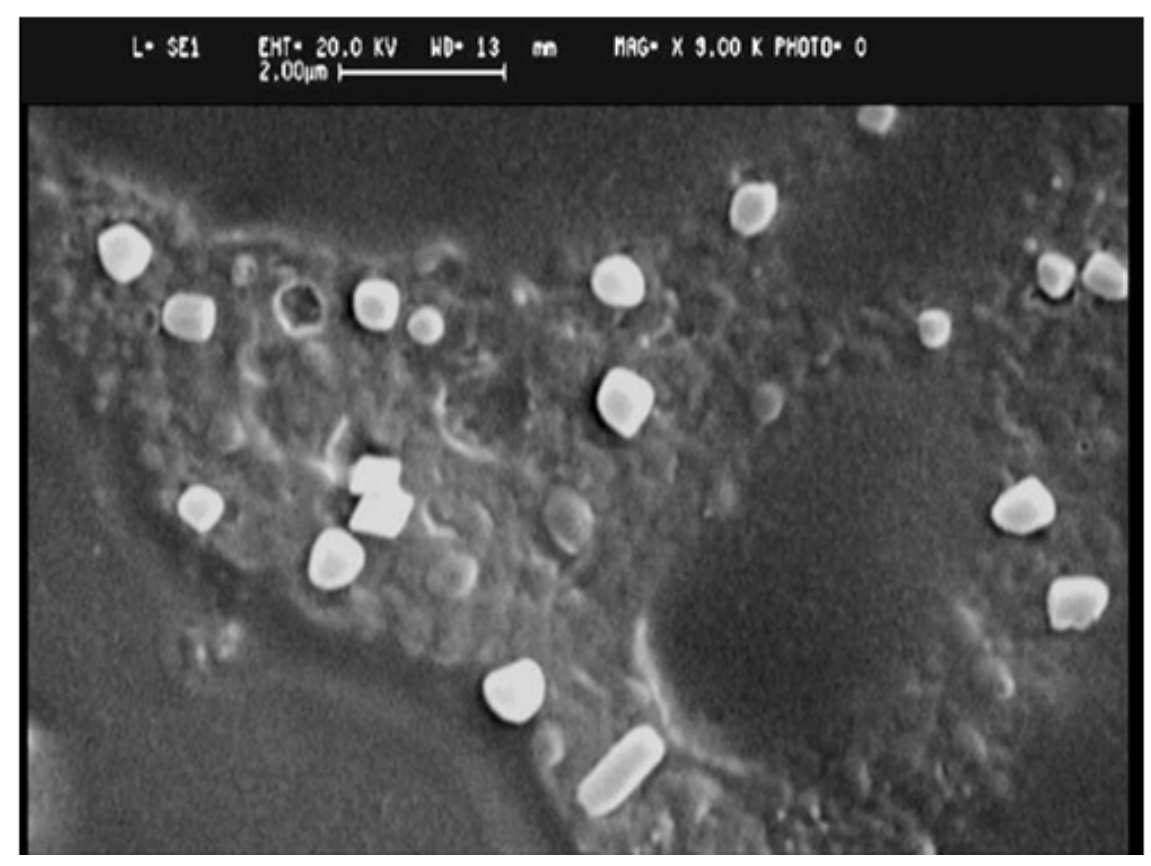

Figure 5. Morphology shifting of the precipitated particles of cetirizine toward more regular form (somehow spherical form) $\left(\mathrm{P}_{\mathrm{ext}}=220\right.$ bar, $\mathrm{T}_{\text {ext }}=308 \mathrm{~K}, \mathrm{~L}_{\text {nozzle }}=5 \mathrm{~mm}$ and $\left.\mathrm{D}_{\text {nozzle }}=1700 \mu \mathrm{m}\right)$. 


\subsection{Effect of Nozzle Length}

In the third series of experiments, the effect of nozzle length on the mean particle size of the precipitated particles was investigated ranging it between 2 - $11 \mathrm{~mm}$ while the other operational conditions were held constant as demonstrated in Table 1 . The obtained results demonstrated that as the nozzle length increases larger particle in size are precipitated. In more details, investigation on Table 3 shows that an increase in nozzle length will cause an increase in the mean particle size of the precipitated particles (see Figure 6). When the capillary length is increased, the precipitation starts inside the capillary, so the particle size of the precipitated particles in long nozzle was bigger than that in the short one [47].

Similarly, Wang et al. [44] and Yildiz et al. [45], Hezave et al. [32] [35] reported an increase in the mean particle size of the precipitated particles of titanocene dichloride, salicylic acid and mefenamic acid, ibuprofen and ketoprofen by increasing the nozzle length. They related the increase of mean particle size by increasing the nozzle length to this fact that, when the length of the capillary is smaller, pressure reduction starts earlier in the expansion device, even in the upstream of the capillary. On the other hand, as the pressure reduction starts earlier, more gradual decrease of the pressure is expected instead of a more rapid expansion in the shorter capillary compared to the longer one. In contrast to the obtained results in the current investigation and those reported in the previously published literature, Kayrak et al. [47] and Hezave et al. [30] reported a contradicting results for micronization of ibuprofen and diclofenac. They have been described this contradicting results as follow. A reduction in the length of the capillary causes earlier pressure reduction in the expansion device, even in the upstream of the capillary. Due to earlier start in pressure reduction, more gradual decrease of the pressure is expected rather than in a shorter capillary. The noteworthy point is that as can be seen in Figure 7 it is completely obvious that as the nozzle length increases, the risk of precipitated particle for agglomeration increases consequently may lead to particles with bigger size. In addition, it can be concluded from the SEM images that the

Table 3. The effect of different operational parameters on the mean particle size of the precipitated particles of cetirizine.

\begin{tabular}{|c|c|c|c|c|c|c|c|}
\hline No. & $\begin{array}{c}\text { Extraction } \\
\text { pressure (bar) }\end{array}$ & $\begin{array}{c}\text { Extraction } \\
\text { temperature (K) }\end{array}$ & $\begin{array}{c}\text { Nozzle } \\
\text { Length } \\
(\mathrm{mm})\end{array}$ & $\begin{array}{c}\text { Effective } \\
\text { Nozzle } \\
\text { Diameter } \\
(\mathrm{mm})\end{array}$ & $\begin{array}{c}\text { Mean } \\
\text { particle } \\
\text { diameter } \\
(\mu \mathrm{m})\end{array}$ & $\begin{array}{c}\text { Standard } \\
\text { deviation } \\
\quad(\mu \mathrm{m})\end{array}$ & $\begin{array}{c}\text { 95\% confidence } \\
\text { interval }(\mu \mathrm{m})\end{array}$ \\
\hline \multicolumn{8}{|c|}{ Effect of extraction pressure } \\
\hline 1 & 160 & 318 & 5 & 1700 & 12.68 & \pm 3.31 & $9.37-15.99$ \\
\hline 2 & 180 & 318 & 5 & 1700 & 10.98 & \pm 3.01 & 7.97 - 13.99 \\
\hline 3 & 200 & 318 & 5 & 1700 & 8.32 & \pm 2.91 & $5.41-11.23$ \\
\hline 4 & 220 & 318 & 5 & 1700 & 7.60 & \pm 2.50 & $5.10-10.10$ \\
\hline \multicolumn{8}{|c|}{ Effect of extraction temperature } \\
\hline 5 & 220 & 308 & 5 & 1700 & 5.15 & \pm 2.15 & $3.00-7.30$ \\
\hline 6 & 220 & 318 & 5 & 1700 & 7.60 & \pm 2.50 & $5.10-10.10$ \\
\hline 7 & 220 & 328 & 5 & 1700 & 9.42 & \pm 4.23 & $5.19-13.65$ \\
\hline \multicolumn{8}{|c|}{ Effect of nozzle length } \\
\hline 8 & 220 & 308 & 2 & 1000 & 2.81 & \pm 1.10 & $1.71-3.91$ \\
\hline 9 & 220 & 308 & 5 & 1000 & 3.67 & \pm 1.56 & $2.11-5.23$ \\
\hline 10 & 220 & 308 & 8 & 1000 & 5.15 & \pm 2.15 & $3.00-7.30$ \\
\hline 11 & 220 & 308 & 11 & 1000 & 5.25 & \pm 2.33 & $2.92-7.58$ \\
\hline \multicolumn{8}{|c|}{ Effect of effective nozzle diameter } \\
\hline 12 & 220 & 308 & 5 & 450 & 0.52 & \pm 0.21 & $0.31-0.73$ \\
\hline 13 & 220 & 308 & 5 & 650 & 0.72 & \pm 0.33 & $0.39-1.05$ \\
\hline 14 & 220 & 308 & 5 & 1000 & 3.67 & \pm 1.56 & $2.11-5.23$ \\
\hline 15 & 220 & 308 & 5 & 1700 & 5.15 & \pm 2.15 & $3.00-7.30$ \\
\hline
\end{tabular}




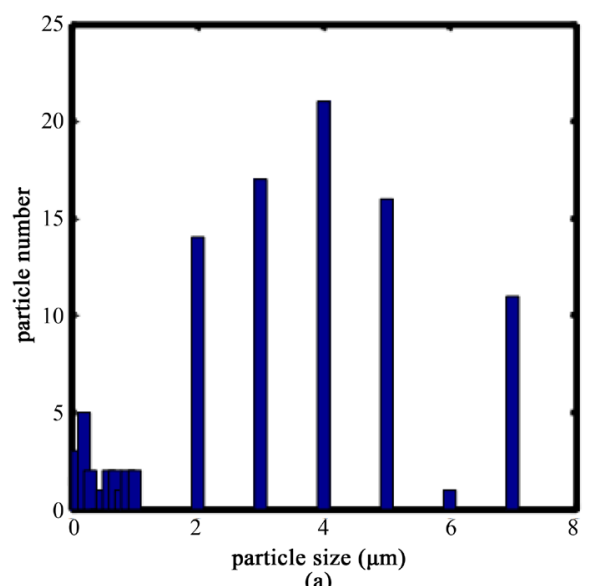

(a)

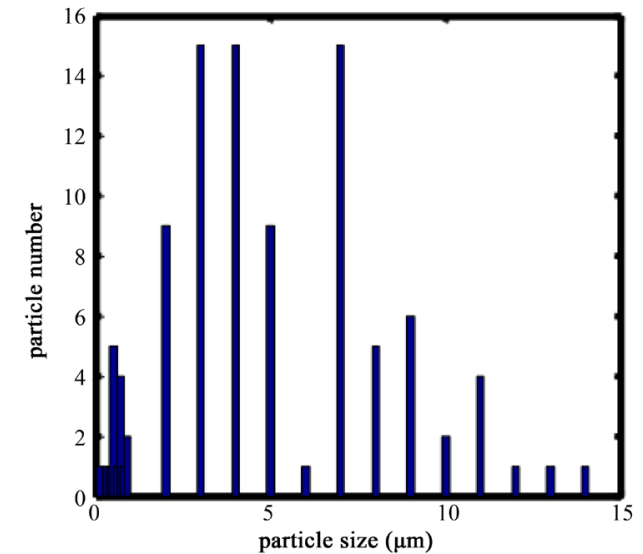

(c)

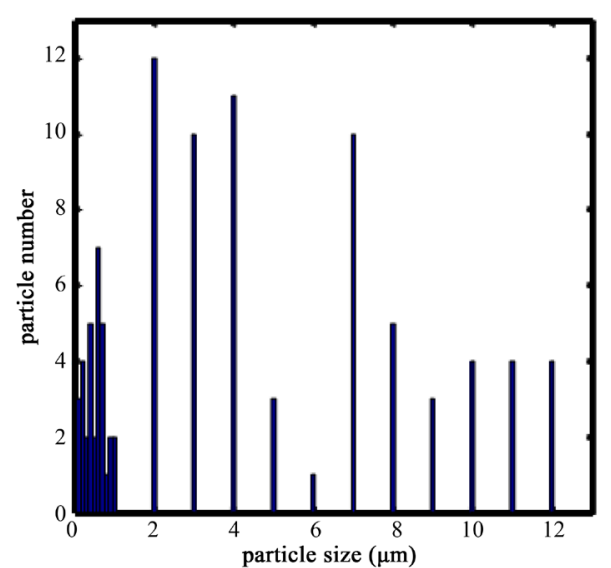

(b)

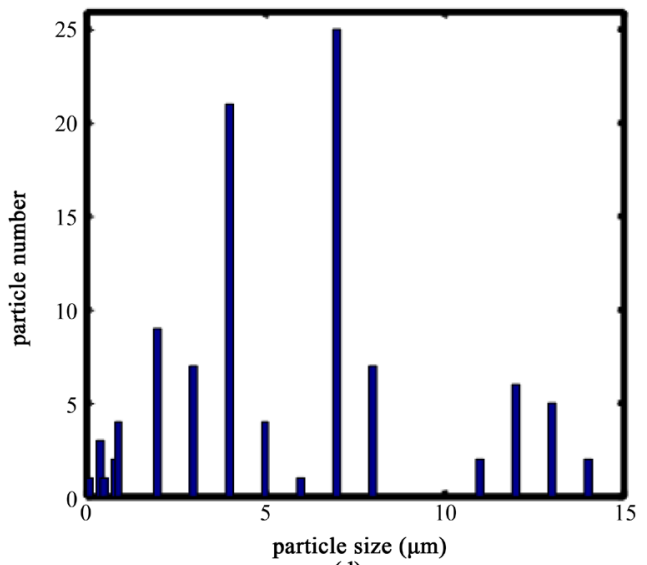

(d)

Figure 6. Effect of nozzle length on the particle size distribution of the precipitated particles of cetirizine during RESS process, (a) $2 \mathrm{~mm}$, (b) $5 \mathrm{~mm}$, (c) $8 \mathrm{~mm}$ and $11 \mathrm{~mm}\left(\mathrm{P}_{\text {ext }}=220\right.$ bar, $\mathrm{T}_{\text {ext }}=308 \mathrm{~K}$ and $\mathrm{D}_{\text {nozzle }}$ $=1000 \mu \mathrm{m})$.

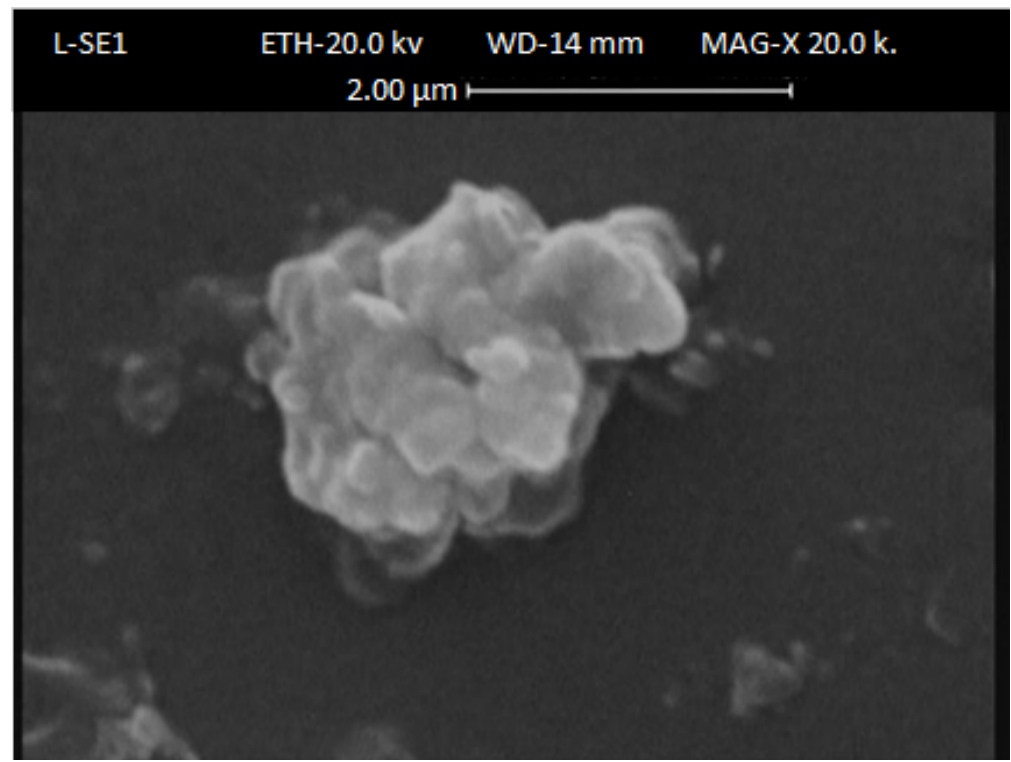

Figure 7. Agglomerated particles of the precipitated cetirizine particles $\left(\mathrm{P}_{\text {ext }}=220 \mathrm{bar}, \mathrm{T}_{\text {ext }}=308 \mathrm{~K}\right.$, $\mathrm{L}_{\text {nozzle }}=2 \mathrm{~mm}$ and $\left.\mathrm{D}_{\text {nozzle }}=1000 \mu \mathrm{m}\right)$. 
precipitated particles of the cetirizine experienced narrow particle size distribution with more spherical shape morphology (see Figure 8).

\subsection{Effect of Nozzle Diameter}

At the last series of experiments, the effect of nozzle diameter on the size of the cetirizine particles was investigated by ranging this parameter between $450 \mu \mathrm{m}$ to $1700 \mu \mathrm{m}$. The obtained results revealed that increasing the nozzle diameter from $450 \mu \mathrm{m}$ to $1700 \mu \mathrm{m}$ leads to an increase in the mean particle size of the precipitated particles from $0.52 \mu \mathrm{m}$ to $5.15 \mu \mathrm{m}$ (see Figure 9). In addition, a closer examination in the image analysis of the obtained results it can be concluded that, a reduction in nozzle diameter not only leading to a reduction in particle size but also leading to a narrow particle size distribution compared with the larger nozzle diameter (see Figure 10).

Finally, examining the SEM images not only revealed that particle size distribution of the precipitated cetirizine particles become narrower but also the particles move toward more spherical morphology (see Figure 11).

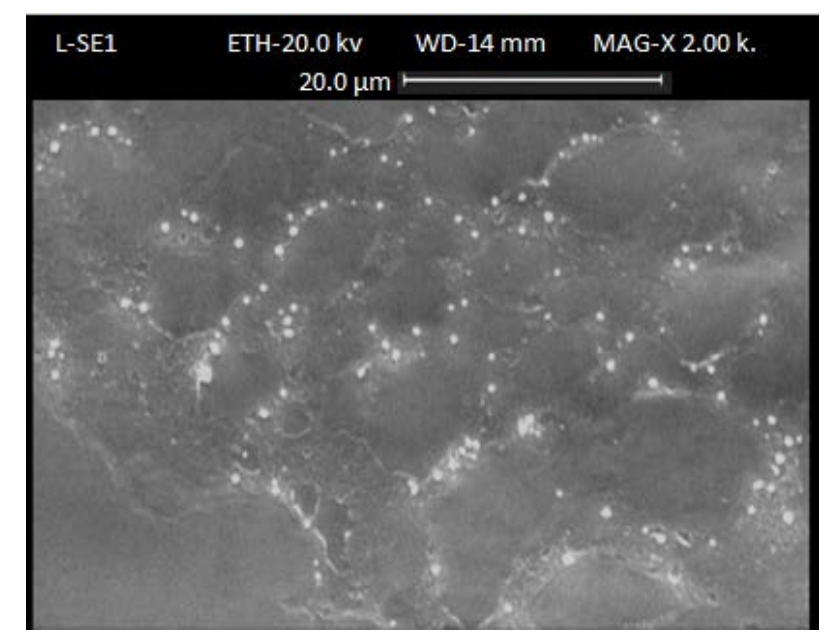

Figure 8. Spherical shape morphology and narrow particle size distribution of the precipitated particles of cetirizine $\left(\mathrm{P}_{\text {ext }}=220 \mathrm{bar}\right.$, $\mathrm{T}_{\text {ext }}=308 \mathrm{~K}, \mathrm{~L}_{\text {nozzle }}=2 \mathrm{~mm}$ and $\left.\mathrm{D}_{\text {nozzle }}=1000 \mu \mathrm{m}\right)$.

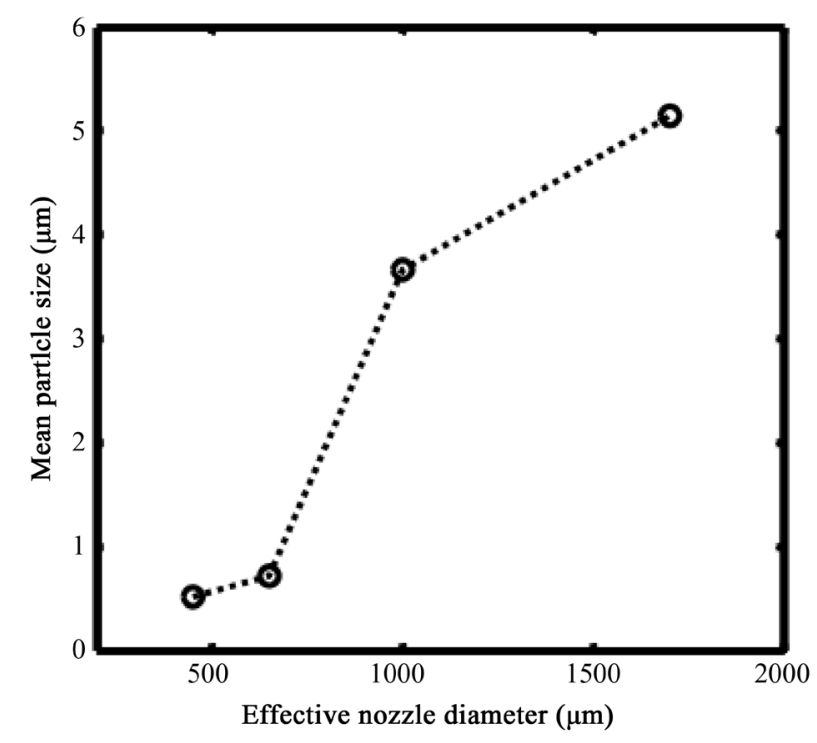

Figure 9. Effect of effective nozzle diameter on the mean particle size of the precipitated particles of cetirizine. 

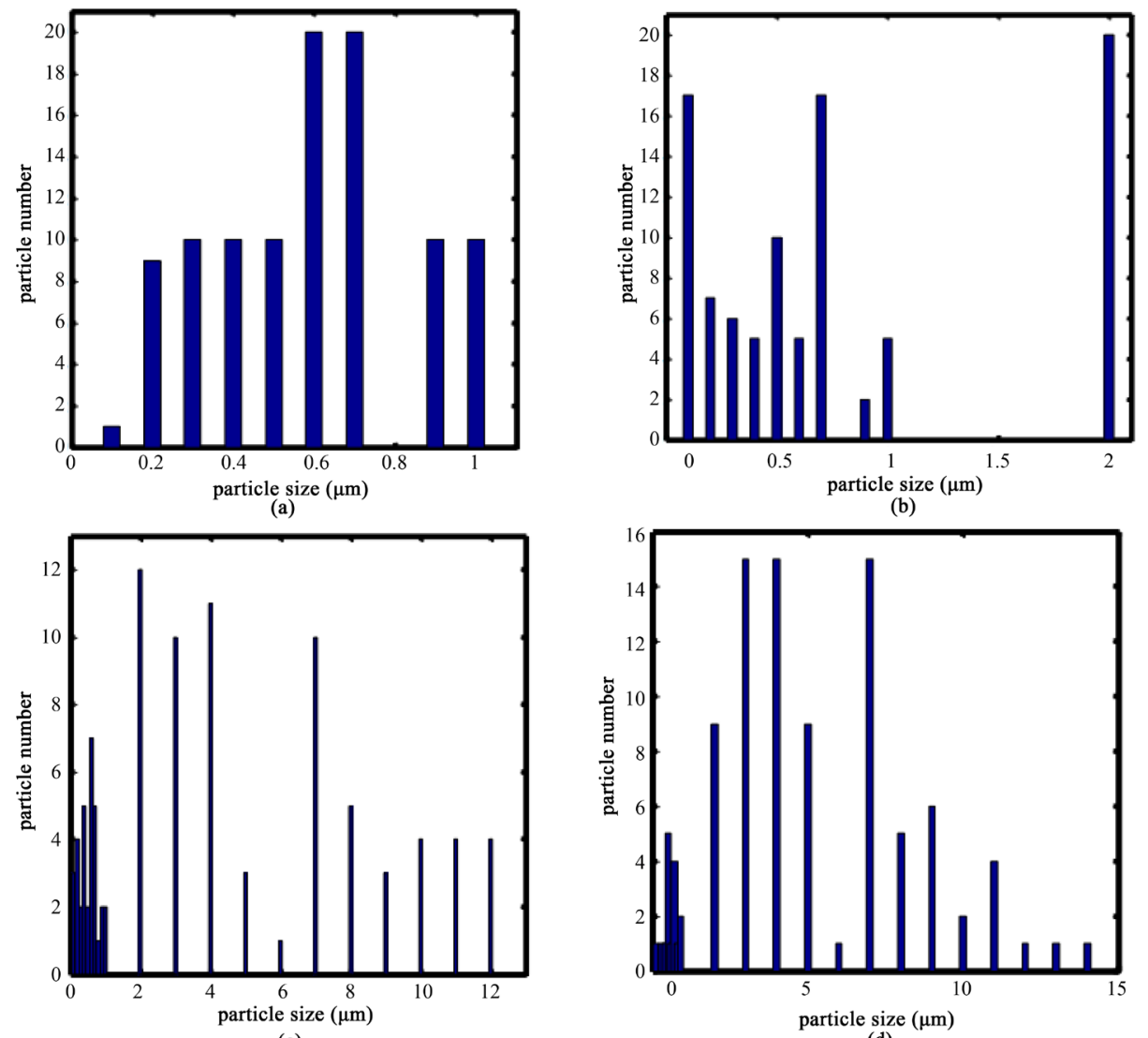

(c)

(d)

Figure 10. The effect of effective nozzle diameter on the particle size distribution of the precipitated particles of the cetirizine, (a) $450 \mu \mathrm{m}$, (b) $650 \mu \mathrm{m}$, (c) $1000 \mu \mathrm{m}$ and (d) $1700 \mu \mathrm{m}\left(\mathrm{P}_{\text {ext }}=220 \mathrm{bar}, \mathrm{T}_{\text {ext }}=308 \mathrm{~K}\right.$ and $\mathrm{L}_{\text {nozzle }}=5 \mathrm{~mm}$ ).

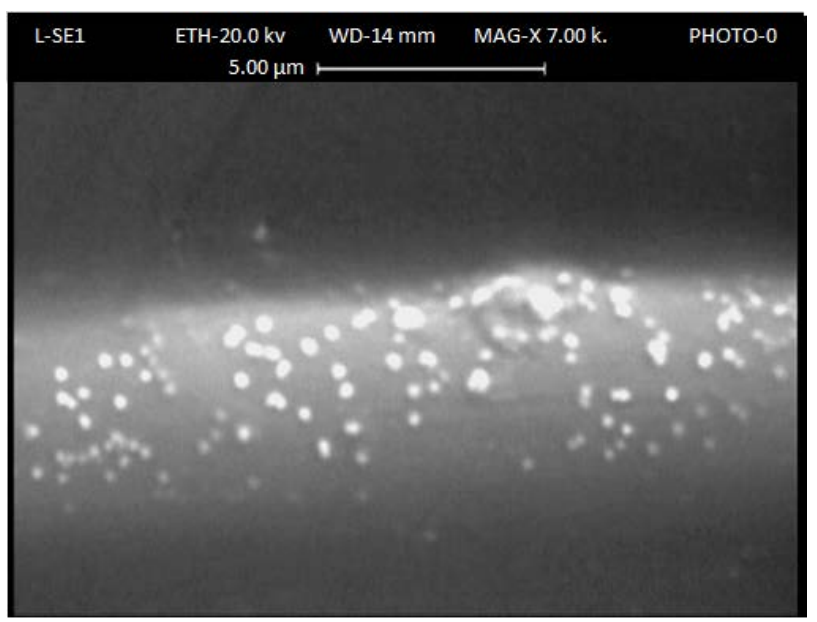

Figure 11. Effect of nozzle diameter on the morphology and uniformity of the precipitated particles $\left(\mathrm{P}_{\text {ext }}=220\right.$ bar, $\mathrm{T}_{\text {ext }}=308 \mathrm{~K}$ and $\mathrm{L}_{\text {nozzle }}=5 \mathrm{~mm}$ and $\left.\mathrm{D}_{\text {nozzle }}=450 \mu \mathrm{m}\right)$.

\section{Conclusion}

In the current study, the efficiency and applicability of RESS process for producing micro-size particles of cetirizine were investigated. For this purpose, a systematic series of experiments was performed to find the optimum 
operational conditions of extraction pressure and temperature, nozzle length and nozzle diameter leading to producing the micron-size particles of cetirizine while carbon dioxide was selected as the supercritical fluid. The obtained results demonstrated that an increase in the extraction pressure leads to a reduction in the particle size, while for other three parameters including nozzle length, extraction temperature and nozzle diameter, an increase leads to an increase in the size of precipitated particles. Also, the obtained results demonstrated that among the examined parameters, extraction pressure and nozzle diameter introduced the highest influence on the reduction of the cetirizine particle diameter. Furthermore, the SEM analysis revealed that the RESS process not only is able to reduce the particle size but also is able to modify the particle morphology from irregular shape to somehow spherical shape. Totally, based on the obtained results it can be concluded that RESS process is an applicable and feasible tool for producing the micron- and submicron-size particles of poorly soluble cetirizine particles.

\section{References}

[1] Pouton, C.W. (2006) Formulation of Poorly Water-Soluble Drugs for Oral Administration: Physicochemical and Physiological Issues and the Lipid Formulation Classification System. European Journal of Pharmaceutical Sciences, 29, 278-287. http://dx.doi.org/10.1016/j.ejps.2006.04.016

[2] Lieberman, H.A., Rieger, M.M. and Banker, G.S. (1996) Pharmaceutical Dosage Forms—Disperse Systems. 2nd Edition, Informa Health Care.

[3]

[4] Rasenack, N. and Müller, B.W. (2004) Micron-Size Drug Particles: Common and Novel Micronization Techniques. Pharmaceutical Development and Technology, 9, 1-13. http://dx.doi.org/10.1081/PDT-120027417

[5] Chang, C.J. and Randolph, A.D. (1989) Precipitation of Microsize Organic Particles from Supercritical Fluids. AIChE Journal, 35, 1876-1882. http://dx.doi.org/10.1002/aic.690351114

[6] Debenedetti, P.G., Tom, J.W., Kwauk, X. and Yeo, S.D. (1993) Rapid Expansion of Supercritical Solutions (RESS): Fundamentals and Applications. Fluid Phase Equilibria, 82, 311-321. http://dx.doi.org/10.1016/0378-3812(93)87155-T

[7] Matson, D.W., Fulton, J.L., Petersen, R.C. and Smith, R.D. (1987) Rapid Expansion of Supercritical Fluid Solutions: Solute Formation of Powders, Thin Films, and Fibers. Industrial \& Engineering Chemistry Research, 26, 2298-2306. http://dx.doi.org/10.1021/ie00071a021

[8] Mawson, S., Johnston, K.P., Combes, J.R. and Desimone, J.M. (1995) Formation of Poly(1,1,2,2-tetrahydroperfluorodecyl Acrylate) Submicron Fibers and Particles from Supercritical Carbon Dioxide Solutions. Macromolecules, 28, 3182-3191. http://dx.doi.org/10.1021/ma00113a021

[9] Mishima, K., Matsuyama, K., Tanabe, D., Yamauchi, S., Young, T.J. and Johnston, K.P. (2000) Microencapsulation of Proteins by Rapid Expansion of Supercritical Solution with a Nonsolvent. AIChE Journal, 46, 857-865. http://dx.doi.org/10.1002/aic.690460418

[10] Jung, J. and Perrut, M. (2001) Particle Design Using Supercritical Fluids: Literature and Patent Survey. The Journal of Supercritical Fluids, 20, 179-219. http://dx.doi.org/10.1016/S0896-8446(01)00064-X

[11] Hezave, A.Z. and Esmaeilzadeh, F. (2010) Micronization of Drug Particles via RESS Process. The Journal of Supercritical Fluids, 52, 84-98. http://dx.doi.org/10.1016/j.supflu.2009.09.006

[12] McHugh, M.A. and Krukonis, V.J. (1994) Supercritical Fluid Extraction: Principles and Practice. 2nd Edition, Butterworth-Heinemann, Boston.

[13] Domingo, C., Berends, E. and van Rosmalen, G.M. (1997) Precipitation of Ultrafine Organic Crystals from the Rapid Expansion of Supercritical Solutions over a Capillary and a Frit Nozzle. The Journal of Supercritical Fluids, 10, 39-55. http://dx.doi.org/10.1016/S0896-8446(97)00011-9

[14] Reverchon, E., Osseo, L.S. and Gorgoglione, D. (1994) Supercritical $\mathrm{CO}_{2}$ Extraction of Basil Oil: Characterization of Products and Process Modeling. The Journal of Supercritical Fluids, 7, 185-190. http://dx.doi.org/10.1016/0896-8446(94)90024-8

[15] Reverchon, E. (1997) Supercritical Fluid Extraction and Fractionation of Essential Oils and Related Products. The Journal of Supercritical Fluids, 10, 1-37. http://dx.doi.org/10.1016/S0896-8446(97)00014-4

[16] Liu, G.T. and Nagahama, K. (1996) Application of Rapid Expansion of Supercritical Solutions in the Crystallization Separation. Industrial \& Engineering Chemistry Research, 35, 4626-4634. http://dx.doi.org/10.1021/ie960142v

[17] Alessi, A., Cortesi, A., Kikic, I., Foster, N.R., Macnaughton, S.J. and Colombo, I. (1996) Particle Production of Steroid Drugs Using Supercritical Fluid Processing. Industrial \& Engineering Chemistry Research, 35, 4718-4726. 
http://dx.doi.org/10.1021/ie960202x

[18] Phillips, E.M. and Stella, V.J. (1993) Rapid Expansion from Supercritical Solutions: Application to Pharmaceutical Processes. International Journal of Pharmaceutics, 94, 1-10. http://dx.doi.org/10.1016/0378-5173(93)90002-W

[19] Türk, M., Hils, P., Helfgen, B., Schaber, K., Martin, H.-J. and Wahl, M.A. (2002) Micronization of Pharmaceutical Substances by the Rapid Expansion of Supercritical Solutions (RESS): A Promising Method to Improve Bioavailability of Poorly Soluble Pharmaceutical Agents. The Journal of Supercritical Fluids, 22, 75-84. http://dx.doi.org/10.1016/S0896-8446(01)00109-7

[20] Oliveira, J.V., Pinto, J.C. and Dariva, C. (2005) Application of a Modified RESS Process for Polypropylene Microparticle Production. Fluid Phase Equilibria, 228-229, 381-388. http://dx.doi.org/10.1016/j.fluid.2004.10.005

[21] Debenedetti, P.G., Tom, J.W., Kwauk, X. and Yeo, S.D. (1993) Rapid Expansion of Supercritical Solutions (RESS): Fundamentals and Applications. Fluid Phase Equilibria, 82, 311-321. http://dx.doi.org/10.1016/0378-3812(93)87155-T

[22] Hirunsit, P., Huang, Z., Srinophakun, T., Charoenchaitrakool, M. and Kawi, S. (2005) Particle Formation of Ibuprofen-Supercritical $\mathrm{CO}_{2}$ System from Rapid Expansion of Supercritical Solutions (RESS): A Mathematical Model. Powder Technology, 154, 83-94. http://dx.doi.org/10.1016/j.powtec.2005.03.020

[23] Subra, P., Berroy, P., Vega, A. and Domingo, C. (2004) Process Performances and Characteristics of Powders Produced Using Supercritical $\mathrm{CO}_{2}$ as Solvent and Antisolvent. Powder Technology, 142, 13-22. http://dx.doi.org/10.1016/j.powtec.2004.03.004

[24] Hernandez, R.S., Ruiz-Trevino, F.A., Ortiz-Estrada, C., Luna-Barcenas, G., Prokhorov, Y., Alvarado, J.F.J. and Sanchez, I.C. (2009) Chitin Microstructure Formation by Rapid Expansion Techniques with Supercritical Carbon Dioxide. Industrial \& Engineering Chemistry Research, 48, 769-778. http://dx.doi.org/10.1021/ie800084x

[25] Tom, J.W., Debenedetti, P.G. and Jerome, R. (1994) Precipitation of Poly(l-lactic Acid) and Composite Poly(l-lactic Acid)-Pyrene Particles by Rapid Expansion of Supercritical Solutions. The Journal of Supercritical Fluids, 7, 9-29. http://dx.doi.org/10.1016/0896-8446(94)90003-5

[26] Tom, J.W. and Debenedetti, P.G. (1991) Formation of Bioerodible Polymeric Microspheres and Microparticles by Rapid Expansion of Supercritical Solutions. Biotechnology Progress, 7, 403-411. http://dx.doi.org/10.1021/bp00011a004

[27] Huang, J. and Moriyoshi, T. (2006) Fabrication of Fine Powders by RESS with a Clearance Nozzle. The Journal of Supercritical Fluids, 37, 292-297. http://dx.doi.org/10.1016/j.supflu.2005.11.024

[28] Subra, P., Berroy, P., Saurina, J. and Domingo, C. (2004) Influence of Expansion Conditions on the Characteristics of Cholesterol Crystals Analyzed by Statistical Design. The Journal of Supercritical Fluids, 31, 313-322. http://dx.doi.org/10.1016/j.supflu.2003.11.009

[29] Kayrak, D., Akman, U. and Hortacsu, O. (2003) Micronization of Ibuprofen by RESS. The Journal of Supercritical Fluids, 26, 17-31. http://dx.doi.org/10.1016/S0896-8446(02)00248-6

[30] Hezave, A.Z. and Esmaeilzadeh, F. (2011) The Effects of RESS Parameters on the Diclofenac Particle Size. Advanced Powder Technology, 22, 587-595. http://dx.doi.org/10.1016/j.apt.2010.08.010

[31] Hezave, A.Z., Aftab, S. and Esmaeilzadeh, F. (2010) Micronization of Creatine Monohydrate via Rapid Expansion of Supercritical Solution (RESS). The Journal of Supercritical Fluids, 55, 316-324. http://dx.doi.org/10.1016/j.supflu.2010.05.009

[32] Hezave, A.Z. and Esmaeilzadeh, F. (2010) Micronization of Drug Particles via RESS Process. The Journal of Supercritical Fluids, 52, 84-98. http://dx.doi.org/10.1016/j.supflu.2009.09.006

[33] Hezave, A.Z. and Esmaeilzadeh, F. (2010) Investigation of the Rapid Expansion of Supercritical Solution Parameters Effects on Size and Morphology of Cephalexin Particles. Journal of Aerosol Science, 41, 1090-1102. http://dx.doi.org/10.1016/j.jaerosci.2010.08.004

[34] Hezave, A.Z. and Esmaeilzadeh, F. (2010) Crystallization of Micro Particles of Sulindac Using Rapid Expansion of Supercritical Solution. Journal of Crystal Growth, 312, 3373-3383. http://dx.doi.org/10.1016/j.jcrysgro.2010.07.033

[35] Hezave, A.Z., Aftab, S. and Esmaeilzadeh, F. (2010) Micronization of Ketoprofen by the Rapid Expansion of Supercritical Solution Process. Journal of Aerosol Science, 41, 821-833. http://dx.doi.org/10.1016/j.jaerosci.2010.01.006

[36] Hezave, A.Z., Mowla, A. and Esmaeilzadeh, F. (2011) Cetirizine Solubility in Supercritical $\mathrm{CO}_{2}$ at Different Pressures and Temperatures. The Journal of Supercritical Fluids, 58, 198-203. http://dx.doi.org/10.1016/j.supflu.2011.05.017

[37] Hezave, A.Z. and Esmaeilzadeh, F. (2012) Recrystallization of Microparticles of Fenoprofen Using Rapid Expansion of Supercritical Solution. Journal of Dispersion Science and Technology, 33, 1106-1115. http://dx.doi.org/10.1080/01932691.2011.599231

[38] Hezave, A.Z. and Esmaeilzadeh, F. (2012) Precipitation of Micronized Piroxicam Particles via RESS. Journal of Dis- 
persion Science and Technology, 33, 990-999. http://dx.doi.org/10.1080/01932691.2011.590438

[39] Hezave, A.Z. and Esmaeilzadeh, F. (2012) Fabrication of Micron Level Particles of Amoxicillin by Rapid Expansion of Supercritical Solution. Journal of Dispersion Science and Technology, 33, 1419-1428. http://dx.doi.org/10.1080/01932691.2011.620883

[40] Hezave, A.Z., Mowla, A. and Esmaeilzadeh, F. (2011) Cetirizine Solubility in Supercritical $\mathrm{CO}_{2}$ at Different Pressures and Temperatures. The Journal of Supercritical Fluids, 58, 198-203. http://dx.doi.org/10.1016/j.supflu.2011.05.017

[41] Poling, B.E., Prausnitz, J.M. and O’Cornnell, J.P. (2004) The Properties of Gases and Liquids. 5th Edition, McGrawHill, New York.

[42] Huang, Z., Sun, G.B., Chiew, Y.C. and Kawi, S. (2005) Formation of Ultrafine Aspirin Particles through Rapid Expansion of Supercritical Solutions (RESS). Powder Technology, 160, 127-134. http://dx.doi.org/10.1016/j.powtec.2005.08.024

[43] Liu, G.T. and Nagahama, K. (1996) Application of Rapid Expansion of Supercritical Solutions in the Crystallization Separation. Industrial \& Engineering Chemistry Research, 35, 4626-4634. http://dx.doi.org/10.1021/ie960142v

[44] Wang, J., Chen, J. and Yang, Y. (2005) Micronization of Titanocene Dichloride by Rapid Expansion of Supercritical Solution and Its Ethylene Polymerization. The Journal of Supercritical Fluids, 33, 159-172. http://dx.doi.org/10.1016/j.supflu.2004.05.006

[45] Yildiz, N., Tuna, Ş., Döker, O. and Çalimli, A. (2007) Micronization of Salicylic Acid and Taxol (Paclitaxel) by Rapid Expansion of Supercritical Fluids (RESS). The Journal of Supercritical Fluids, 41, 440-451. http://dx.doi.org/10.1016/j.supflu.2006.12.012

[46] Reverchon, E., Donsi, G. and Gorgoglione, D. (1993) Salicylic Acid Solubilization in Supercritical $\mathrm{CO}_{2}$ and Its Micronization by RESS. The Journal of Supercritical Fluids, 6, 241-248. http://dx.doi.org/10.1016/0896-8446(93)90034-U

[47] Kayrak, D., Akman, U. and Hortacsu, Ö. (2003) Micronization of Ibuprofen by RESS. The Journal of Supercritical Fluids, 26, 17-31. http://dx.doi.org/10.1016/S0896-8446(02)00248-6 